\title{
Influence of Strut Diameter and Building Direction on Strength of Lattice Structure
}

Pavel Hanzl, Ivana Zetková, Š́rka Cajthamlová

Faculty of Mechanical Engineering, University of West Bohemia. Univerzitní 2732/8, 30614 Pilsen. Czech Republic.

E-mail: hanzlp@rti.zcu.cz, zetkova@rti.zcu.cz, sary21@students.zcu.cz

\begin{abstract}
Metal additive manufacturing provides an efficient way of processing metallic cellular structures. This relatively novel way of production is based on a powder bed which is melted using a powerful laser. Despite the advantages of this production technology, differences in geometry are observed between the CAD model and the manufactured structures. With this in mind, a series of thin struts were made and their geometry analysed using optical-scanning microscopy. Various building directions and strut diameters are studied. The effective stiffness of struts are measured and verified by tensile tests. The results point to higher strength of inclined struts than perpendicular specimens.
\end{abstract}

Keywords: Milling Tool, Topological Optimization, Direct Melting Laser Sintering, Metal Additive Manufacturing

\section{Introduction}

Cellular lattice structures are an effective means for improving the balance between weight and stiffness. Their main applications are currently in aerospace, but their scope will be extended to other industries. These lightweight design elements provide a breakthrough in component design. The lattice structures can be adapted well for multifunctional requirements, especially where space needs to be filled. [6][7] This space can be filled functionally depending on the loading conditions by changing the cell topology and its orientation. The last element which influences the final properties is the material which the structure is made from.

In general, Metal Additive Manufacturing is able to produce complex shapes. However, if the deployment of support structures is limited, such as the production of lattice structures, it is necessary to fulfil the basic assumption of production without support structures. The building orientation must ensure self-support. This means that the angle between the surface of the part and the plane of the building platform should be higher than the critical angle. This should ensure reliable production without defects. Practice shows that there is not strictly one critical angle value. Rather, there is a range of angles over which the quality of the printed surfaces is gradually improved.

The Body Centred Cube (BCC) topology is a good example. The struts are at $35^{\circ}$ to the ground plane, which is usually identical to the plane of the building platform. This orientation is most advantageous for MAM and is very often applied in conjunction with MAM. However, it does not meet the most basic rule for MAM, a self-supporting angle. A self-supporting angle is generally considered to be greater than $40^{\circ}$.

A modified BCC geometry with a $38^{\circ}$ building direction was used for a lightweight milling cutter in papers [4][5] by Hanzl et al. and the present work consists of manufacturing a cellular structure using DMLS and focusing on the structural characterisation at the scale of a single strut. The aim is to establish the real stiffness of the modified BCC topology taking into account the observed defects at this scale.

This issue is researched in connection with Suard [1], who deals with similar tasks in Electron Beam Melting (EBM) technology. Struts with different diameters and orientations relative to the building platform are included. The distribution of mass throughout the struts is investigated using optical-scanning microscope Alicona IFM G4. The struts undergo tensile testing and their measured strength is compared with the value predicted by the CAD model. [1] The results from the measurements and tensile tests can refine the predictions of Finite Element Analyses (FEA), which is very helpful when designing machine components. [8]

\section{Methods and experiment}

The struts are manufactured layer by layer using Direct Metal Laser Sintering (DMLS). The device used for producing the specimens is an EOS M 290. The maximum laser power is $400 \mathrm{~W}$. The material is EOS MaragingSteel MS1, which is classified such as 1.2709 according to European classification. The powder was produced by standard gas atomization. Figure 1 shows the particle size distribution of the powder. The particles are relatively circular. Ten percent of the particles have a diameter less than 10 microns and the maximum measured diameter is less than 150 microns. [2] The process parameters used for melting are the standard ones developed by the EOS manufacturer for $40 \mu \mathrm{m}$ thin layers. The base parameters for melting the core are: laser power $285 \mathrm{~W}$ and scanning speed $960 \mathrm{~m} / \mathrm{s}$.

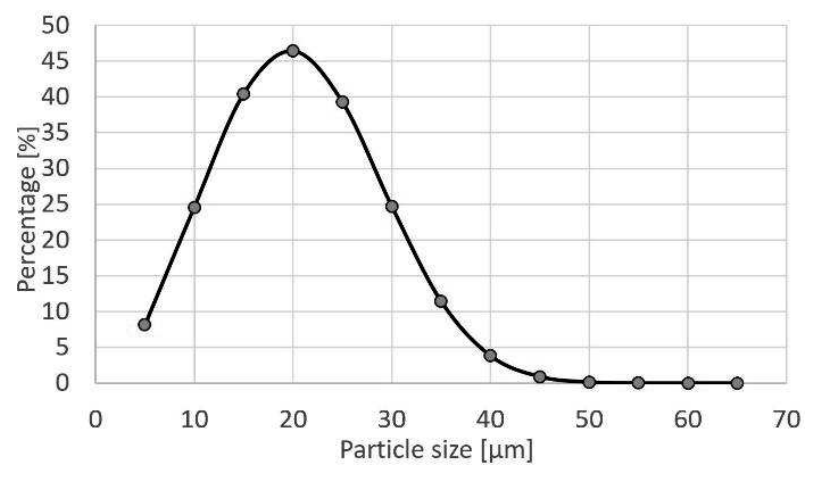

Fig. 1 The particle size distribution of the metal powder according to the Weibull function [2] 


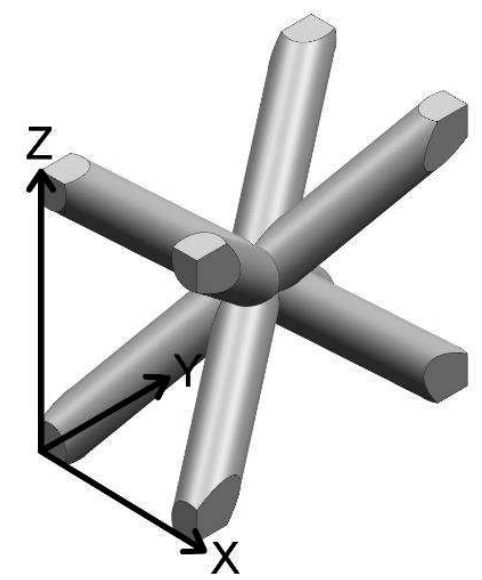

Fig. 2 Modification of basic BCC cell

The surface analyses were carried out on various samples. The differences between the initial CAD model and the geometry of the real struts are highlighted. This identifies the mass distribution throughout the struts. The minimum stiffness is restricted by narrowed cross-section of struts. The deviation from effective volume is described in relation to DMLS technology. The build direction of the struts is designed to predict the real stiffness of the modified $\mathrm{BCC}$ topology for a rotating part, a milling cutter. More about this modification is given in [4].

Strut behaviour depends on build orientation and loading direction. [1] Two basic samples have different build orientations. The first is for reference and its orientation is most suitable for MAM and has the least impact on manufacturing accuracy. The direction is 90 degrees. The second set was inclined to 38 degrees. This inclination was chosen because the results are related to the modified topology of the $\mathrm{BCC}$ lattice structure. This orientation is the same as the struts in the modified BCC topology for the lightweight milling cutter.

For the credibility of the results, each set had 3 series with 5 different diameters. The diameters in each series were $0.86 \mathrm{~mm}, 1 \mathrm{~mm}, 1.19 \mathrm{~mm}, 1.5 \mathrm{~mm}$ and $1.8 \mathrm{~mm}$. The strut diameter $1.19 \mathrm{~mm}$ is the reference because it was used for the lightweight milling cutter. The strut tensile specimens were designed in accordance with the standard CSN EN ISO 6892-1. The work length of the specimen (Lo) is $100 \mathrm{~mm}$ and the shortest overall length allowed is $120 \mathrm{~mm}$. The ratio of diameter to length 1:10 is high and very problematic for production by MAM. Therefore, a special envelope is created around the thin struts. The envelope fixes the struts in position and is essential for producing long specimens. This solution is shown in Figure 3.

The selected struts were scanned by IFM G4 5x. The deviation of measurement with this lens is $0.005 \mu \mathrm{m}$ which was confirmed during calibration tests. Allowed tolerance is $0.015 \mu \mathrm{m}$ with this zoom. The scanning is done using IF Laboratory Measurement Module software and the scans are evaluated using MeasureSuite.

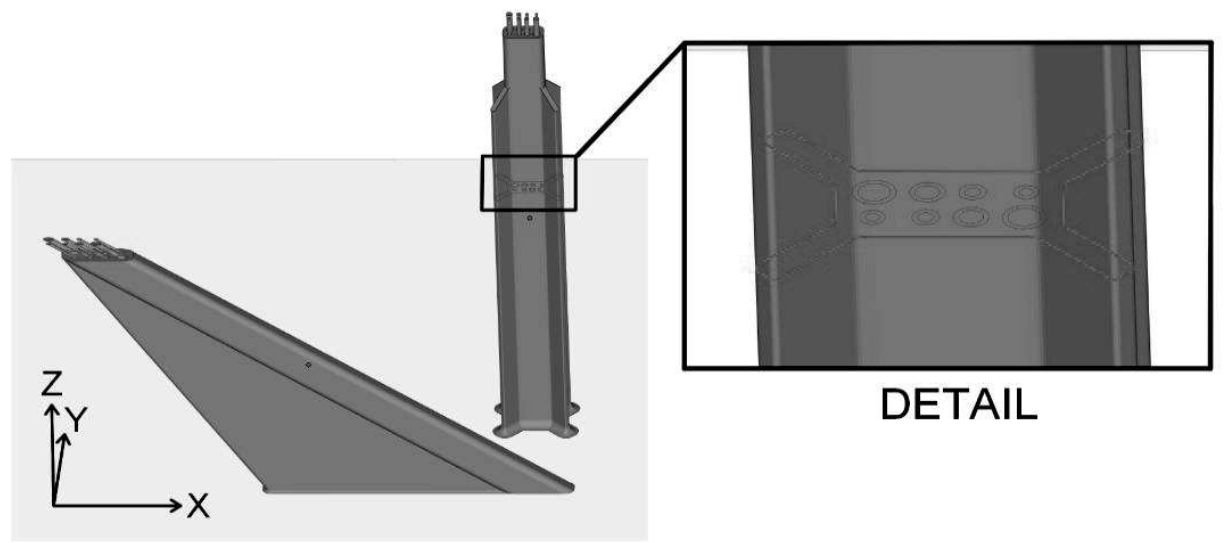

Fig. 3 Build task with the envelope and struts showing the solution for producing long, thin strut specimens.

\section{Results and discussion}

The 3D scans allow the outer characterisation of the struts and determine the minimum cross-section in the monitored area of the struts. Porosity could fluctuate depending on the orientation and process parameters, but it remains lower than $1 \%$ [3]. This means that the struts can be considered as almost fully dense.

As Figure $5 \mathrm{c}$ shows, the surface quality at the bottom of the $38^{\circ}$ inclined struts is very impaired and the metal substrate is missing. This phenomenon is caused by insufficient support of the lower layers and partly due to the unmelted powders that stick to the melt pool at the bottom of the struts. Suard et al. [1] reached a similar conclusion. In addition, they also observed that the roughness on the top of the struts comes from the borders between the melted layers. The corrugation of the roughness is oriented vertical to the build direction with a period of about
$40 \mu \mathrm{m}$, which is the thickness of the layers.

This is the main reason why a limited stiffness of a real strut is expected, because a part of the material does not contribute to the stiffness. The struts without inclination $\left(90^{\circ}\right.$ build direction) exhibit only banding caused by production in layers.

The minimum possible stiffness is suggested based on the restricted cross-section according to the diagrams in Fig. 4 and Fig. 5. The software algorithms evaluate the strut diameter and create its axis from a $3 \mathrm{~mm}$ long scan. The cross-section is examined from the scan. The minimum and maximum peaks are recorded in the diagram (see Fig. 4a and Fig. 5a). The scanned part of the strut in the middle of the strut specimens can be declared as representative for the whole strut specimen.

The ratio of the effective volume is given by the ratio of the content of the inscribed circle to the CAD circle 
content of the strut, see Formula 1. A similar procedure was used by Suard et al. [1] to predict the minimum stiffness. The maximum tensile stress should be less by this ratio than the theoretical CAD model. The properties of the metal material produced by DMLS are as follows: Maximum stress $1170 \mathrm{MPa}$ and yield strength $1060 \mathrm{MPa}$. These values are taken from Zetková [2]. The tensile specimens in her work were produced under the same conditions as our struts. Tensile samples were in accordance with the standard ČSN EN ISO 6892-1 and their diameter was D4. The real limit of stress into the strut is given by Formula 2 .

$$
\begin{gathered}
\boldsymbol{\varphi}=\frac{\boldsymbol{A}_{\text {inscribed circle }}}{\boldsymbol{A}_{\text {CAD }}}[\%] \\
R m_{\text {Effective }}=\varphi \cdot R m_{C A D}[\mathrm{MPa}]
\end{gathered}
$$

\subsection{Impact of Strut orientation}

Surface quality, including the shape of parts printed by DMLS depends on orientation. The same trend can be observed for lattice structures. Scans of specimens under
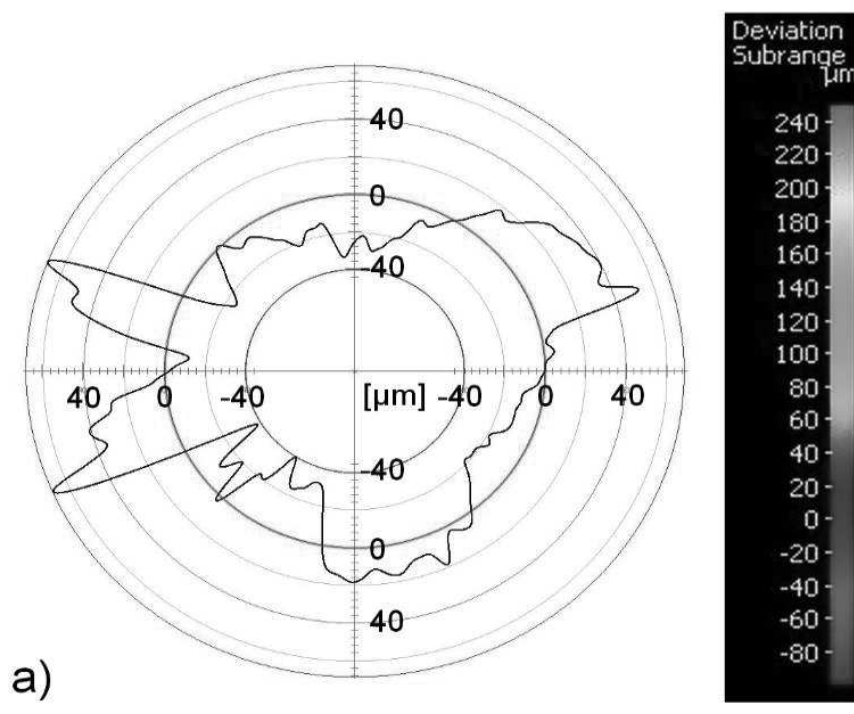

$38^{\circ}$ inclination and $90^{\circ}$ are shown in figures 4 and 5 . Both specimens have the same CAD diameter of $1.19 \mathrm{~mm}$. The ratio of effective volume to $\mathrm{CAD}$ volume is $90 \%$ for the $38^{\circ}$ specimen, whereas the $90^{\circ}$ specimen has $92 \%$. Higher accuracy is achieved with a vertical specimen than with an inclined or horizontal strut specimen. This was also confirmed by Suard et al. [1]. The surface roughness on the top of the inclined strut was $\mathrm{Ra} 7.7 \mu \mathrm{m}, \mathrm{Rq} 9.4 \mu \mathrm{m}$ and $\mathrm{Rz} 45.0 \mu \mathrm{m}$. The values for the vertical specimen were $\mathrm{Ra} 4.7 \mu \mathrm{m}$, Rq $5.9 \mu \mathrm{m}$ and Rz $31.0 \mu \mathrm{m}$. These parameters also confirm the differences between the specimens.

All this suggests that specimens under $38^{\circ}$ will exhibit worse mechanical properties than samples with vertical struts because a large amount of metal mass is missing on the bottoms of all the inclined specimens. Consequently, there is a smaller effective cross-section and higher porosity in these struts. Tensile tests were carried out on a Zwick/Roell Z005 to verify this assumption.

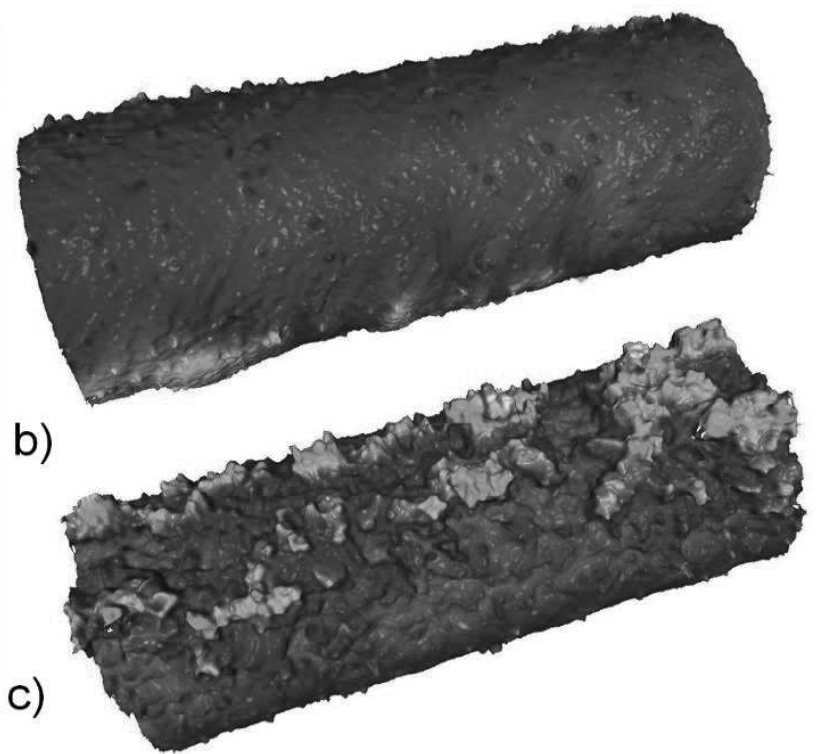

Fig. 4 Analysis of inclined strut with reference diameter $1.19 \mathrm{~mm}$;

a) Diagram of deviation from $1.080 \mathrm{~mm}$ diameter; b) Scan of top side; c) Scan of bottom side
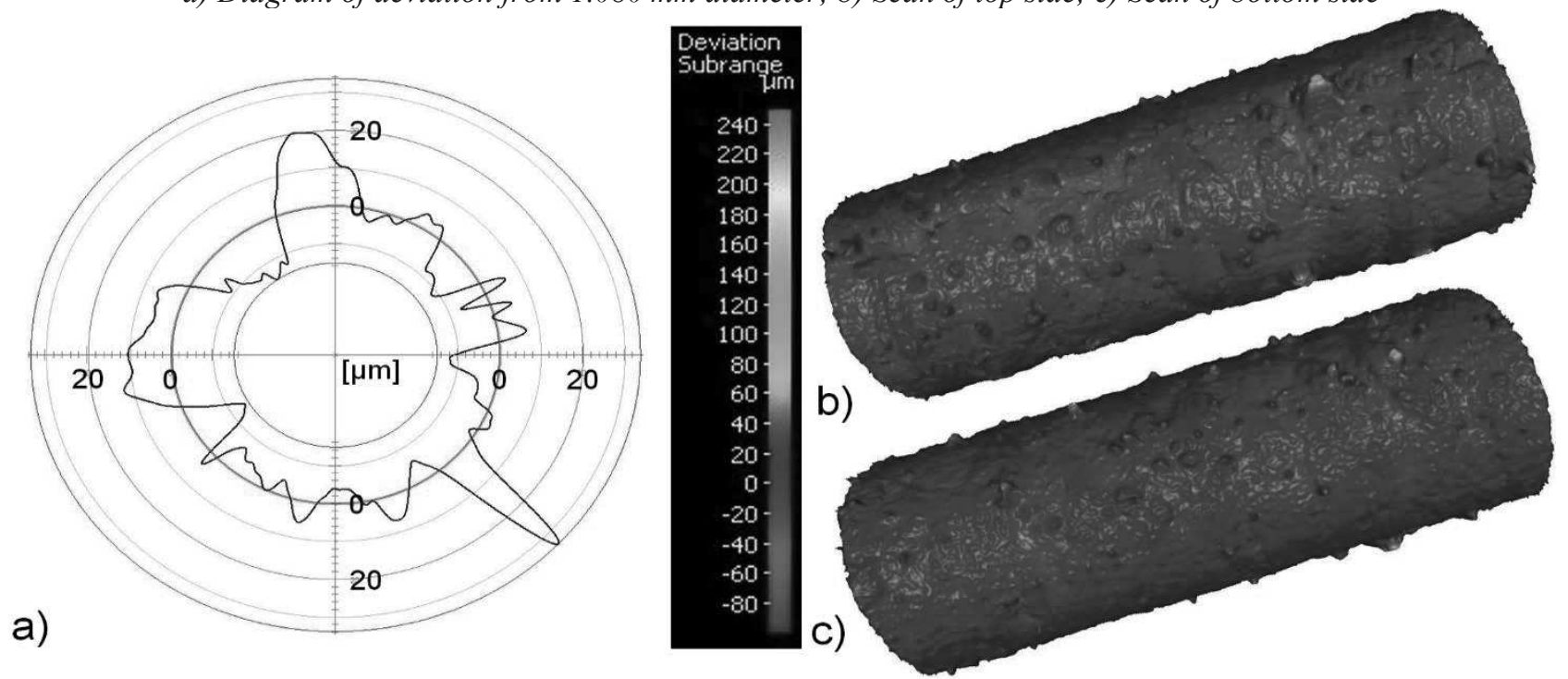

Fig. 5 Analysis of strut with reference diameter $1.19 \mathrm{~mm}$;

a) Diagram of deviation from $1.098 \mathrm{~mm}$ diameter; b) Scan of top side; c) Scan of bottom side 
The tensile tests showed variations between the specimens. The perpendicular specimens achieved $929 \mathrm{MPa}$ (79\% efficiency). The inclined specimens had greater shape deviation from the CAD model, but higher strength of $996 \mathrm{MPa}$ ( $85 \%$ efficient). The stress-strain diagram is shown in Figure 6. However, these values do not correspond with the calculated limit stress (Rmeffective), which are $1076 \mathrm{MPa}$ for the perpendicular sample and 1053 $\mathrm{MPa}$ for the inclined sample.

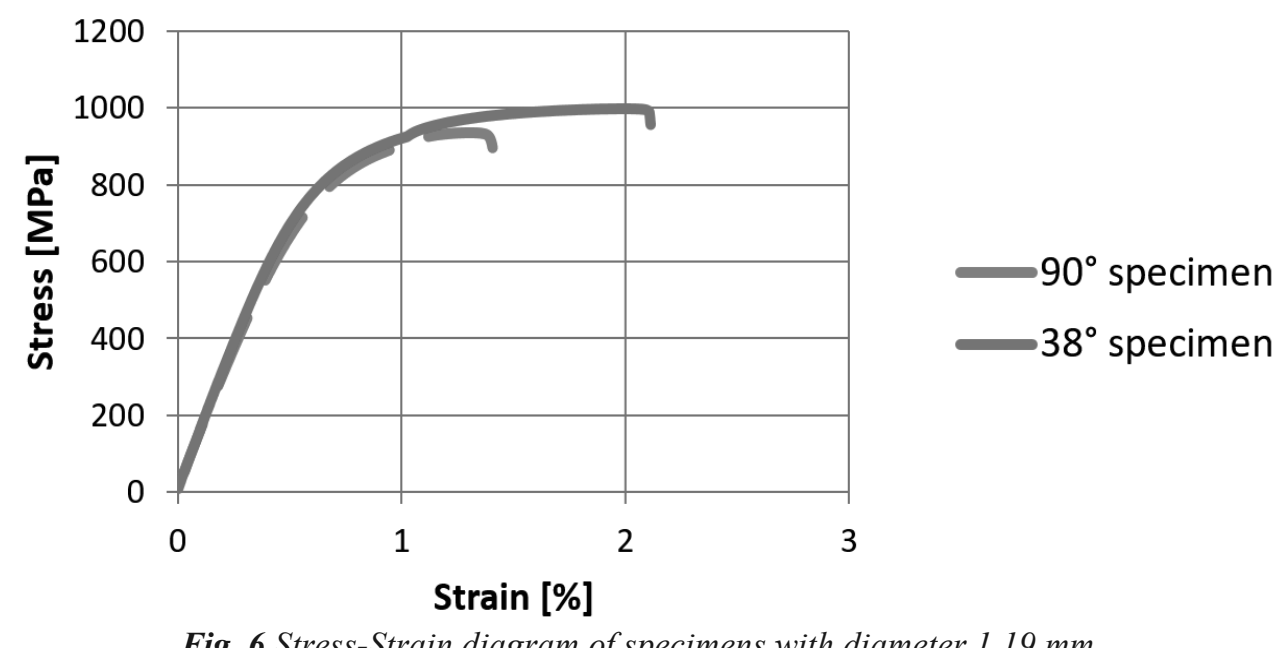

Fig. 6 Stress-Strain diagram of specimens with diameter $1.19 \mathrm{~mm}$

Here is the split between the expected result and the measured values. In fact, the inclined sample has more deteriorated bottom surface quality, but the orientation of its layers to the load axis provides a higher load capacity.
Moreover, its cross-section is not much weakened compared to the $90^{\circ}$ specimen. The orientation of the layers in the struts are shown in Figure 7.

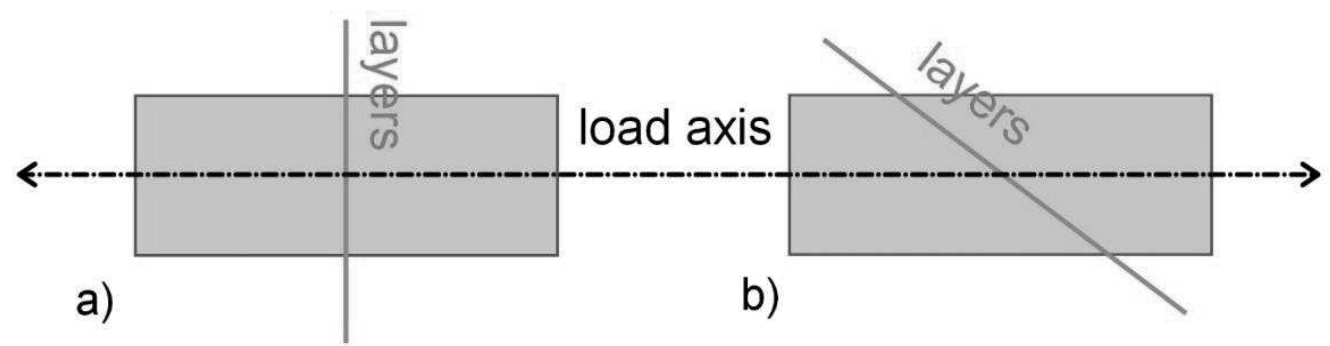

Fig. 7 Orientation of layers in struts; a) $90^{\circ}$ specimens; b) $38^{\circ}$ specimens

\subsection{Impact of Strut diameter}

The significance of the diameter is determined by tensile tests. The measured efficiency with the results of the

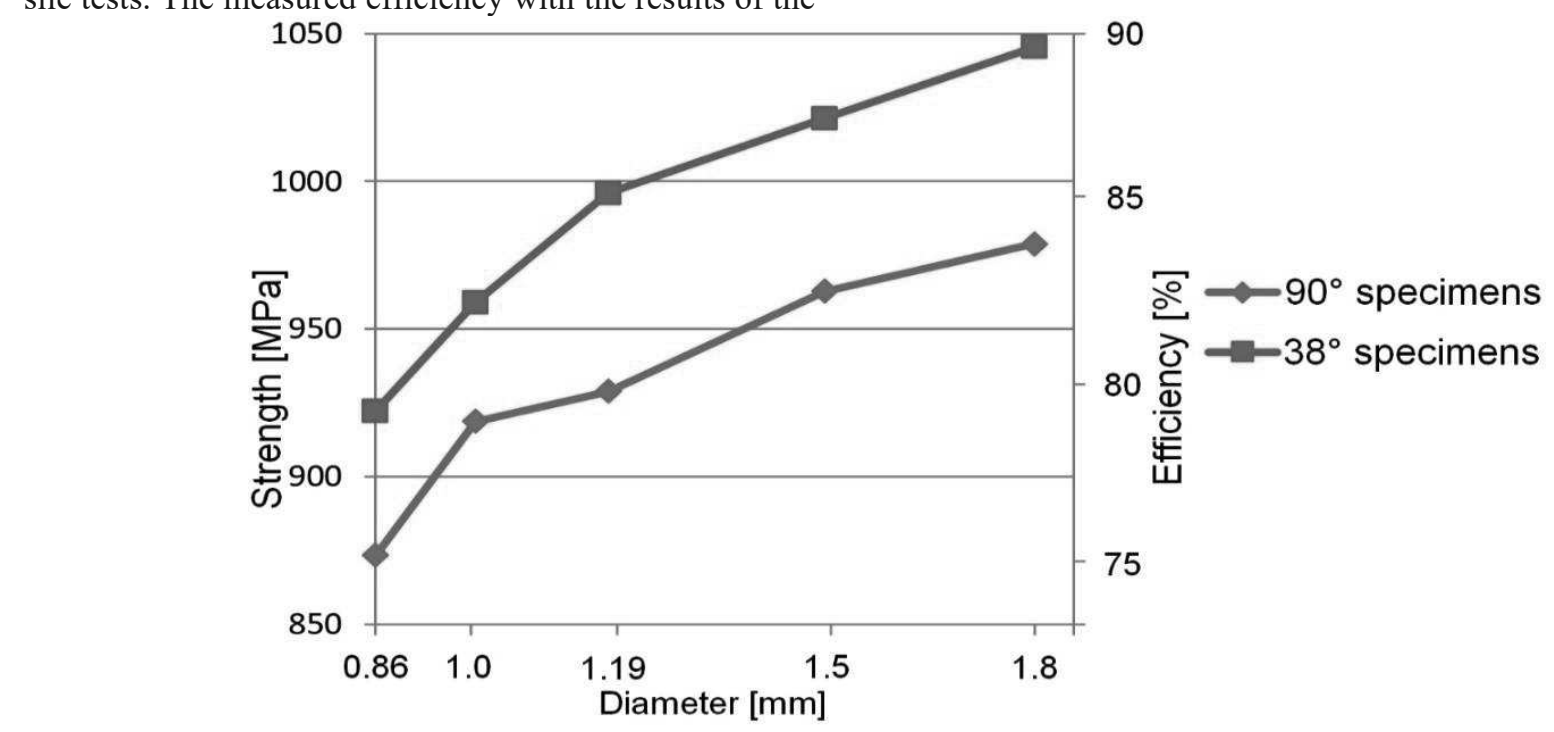

tensile tests are shown in Figure 8. Printed specimens reached lower values of strength, which is reflected in efficiency. Full $100 \%$ efficiency is $1170 \mathrm{MPa}$.

Fig. 8 Strength and efficiency of struts with diameter variation for $38^{\circ}$ and $90^{\circ}$ specimens 
The influence of orientation on the strength of the printed material was confirmed again. The influence of building direction on strength was consistent across the range of testing. Despite higher geometric deviations of the inclined specimens, these specimens had a load capacity on average $5 \%$ higher than the $90^{\circ}$ specimens. This means that the influence of the layer orientation is more significant than the qualitative parameters at the bottom surface of the inclined struts. Further, it was observed that the strength increases with greater diameter. The maximum difference between the smallest and the largest diameter was approximately $125 \mathrm{MPa}$.

\section{Conclusion}

The aim of this paper was to evaluate the influence of using DMLS technology on the stiffness of the basic elements of lattice structures. The laser beam melting process creates a deviation in geometry between the desired and real struts. Significant changes were observed in the shape of the inclined specimens, which were built at a smaller angle to the building platform of the DMLS device.

However, these inclined specimens of the struts showed higher load capacity than the perpendicular struts (with $90^{\circ}$ building direction). This was confirmed across all the tensile tests of the different strut diameters. The layer orientation seems to be the main cause (see Fig.7). Inclined struts have more preferably oriented layers with respect to the tensile load axis. This orientation has a greater influence on the load capacity than larger variations in the strut geometry.

Following these observations, the conclusions and methods of Suard et al. [1] may be incomplete, because they evaluated the stiffness of the lattice struts only on the basis of geometry and porosity. They did not include the microstructural properties of the melted material which is produced layer by layer in the stiffness prediction.

The main output of this paper is the real efficient strength of struts with different diameters and inclinations. For example, the strut with $1.19 \mathrm{~mm}$ and building direction $38^{\circ}$ reaches $996 \mathrm{MPa}$ compared to the standard $1170 \mathrm{MPa}$ for melted material from the same steel. This can be used to increase the accuracy of prediction by FEA, which is easy to use for topologically optimized printed parts with lattice structures.

\section{Acknowledgement}

This paper was supported by the Internal Grant Agency of the University of West Bohemia, project No. SGS2019-008.

\section{References}

[1] SUARD, M., LHUISSIER, P., DENDIEVEL, R., BLANDIN, J., VIGNAT, F., VILLENUVE, F. (2014) Towards Stiffness Prediction of Cellular Structures Made by Electron Beam Melting (EBM). Powder Metallurgy, Powder Metallurgy, Vol. 57, Pp. 190-195

[2] ZETKOVÁ, I. (2017) Complexity of metal mechanical components production by $3 D$ printing, thesis, Faculty of Mechanical Engineering, University of West Bohemia

[3] KUČEROVÁ, L., ZETKOVÁ, I., JANDOVÁ, A., BYSTRIANSKÝ, M. (2019) Microstructural characterisation and in-situ straining of additive-manufactured X3NiCoMoTi 18-9-5 maraging steel, Materials Science and Engineering: A, Vol. 750, Pp. 70-80, ISSN 0921-5093

[4] HANZL, P., ZETKOVA, I. (2019) Benefits of a new approach to designing milling cutter using Metal Additive Manufacturing, Published by Manufacturing Technology, ISSN 1213-2489, June 2019, Vol. 17, No. 3

[5] HANZL, P., ZETKOVA, I. (2019) Specially designed lattice structure for milling cutter supported by FEA, Published by Manufacturing Technology, ISSN 1213-2489, June 2019, Vol. 17, No. 5

[6] VERNON R.A. (2016) Discovering optimal unit cell configuration when designing for additive manufacturing using lattice structures, Thesis, Department of Mechanical and Aerospace Engineering, California State University, Long Beach

[7] SYAM, W.P., JIANWEI, W., ZHAO, B., MASKERY, I., ELMADIH, W., LEACH, R. (2018) Design and analysis of strut-based lattice structures for vibration isolation, Published by Precision Engineering, ISSN 0141-6359, Vol. 52, Pp. 494-506.

[8] BLATNICKÝ, M., DIŽO, J., ŠTAUDEROVÁ, M. (2017) Strength Analysis of a Structure for Attachment of a Winch on SUV, Published by Manufacturing Technology, ISSN 1213-2489, June 2017, Vol. 17, No. 3 